\title{
On Protection of the Miner's Right to Life and Right to Health
}

\author{
Zou Yanhui ${ }^{1}$ \\ ${ }^{1}$ School of Law, Jinan University, Jinan Shandong, China \\ Correspondence: Zou Yanhui, No. 336 Nanxinzhuangxi Road, School of Law, Jinan University, Jinan, Shandong, \\ China. Tel: 86-131-7644-8802. E-mail: zouyh2009@hotmail.com
}

$\begin{array}{lc}\text { Received: April 14, } 2014 & \text { Accepted: April 29, } 2014 \quad \text { Online Published: May 28, } 2014 \\ \text { doi:10.5539/jpl.v7n2p127 } & \text { URL: http://dx.doi.org/10.5539/jpl.v7n2p127 }\end{array}$

\begin{abstract}
Mine accidents occurred frequently in China. The phenomenon of ignoring the miner's right to life and right to health is widespread. On the basis of analyzing the reasons for the infringement of the miner's right to life and right to health, to the existing problems, the article put forward specific measures to protect the miner's right to life and right to health.
\end{abstract}

Keywords: right to life, right to health, miners, social insurance, safety awareness

\section{Introduction}

At present, the lives of miners are deprived ruthlessly in the shocking mine accidents again and again. More miners are suffering from the pneumoconiosis and other occupationally induced diseases. Their right to health is wantonly trampled. The status of frequent infringement of the miner's right to life and right to health has aroused a general concern among the insightful theorists and practitioners. However, for the existing research, most of them only discussed from the production safety perspective. Even if some articles illustrated the protection of the miner's rights, but the rights still involved a variety of rights rather than devoting to the miner's right to life and right to health protection. This shows that the research on the miner's right to life and right to health protection is still lacking. With their blood and tears, thousands and thousands of miners are calling for the establishment of the mechanisms to protect them, particularly the establishment of the system to protect their rights -the right to life and right to health.

\section{The Current Status of the Miner's Right to Life and Right to Health Protection}

\subsection{The Current Status of the Miner's Right to Life Protection}

Talking about the current status of the miner's right to life protection in China, the statistics from the State Administration of Work Safety should be the most convincing. From 2001 to 2010, there were 16,791 national non-coal mine accidents in total, and the death was of 21,251 people, which is the annual average of 1,679 in accidents, and 2,125 in people (State Administration of Work safety, 2011). Facts speak louder than words. Although the situation of the coal mine production safety maintains trending stable and improving in overall, the large number of the total casualty accidents and the death in coal mine accidents in recent years are still shocking. This shows that the situation of the production safety remains grim. It is still not optimistic regarding the miner's right to life protection.

\subsection{The Current Status of the Miner's Right to Health Protection}

The mine accidents will deprive the life of the miners. The occupational diseases will also infringe upon the miner's right to health and even right to life. Taking the top occupational hazards, pneumoconiosis as an example, it is the number one invisible killer to the coal miners. According to the statistics released by the health sector, to the end of 2008, over 700,000 occupational diseases were reported accumulatively. Among them, there is nearly 640,000 pneumoconiosis cases, ranking first in the world. (Lan \& He, 2010) Moreover, the incidence rate of pneumoconiosis is far greater than the actual number of cases reported

\section{The Reasons for the Infringement of the Miner's Right to Life and Right to Health}

The mine accidents happened frequently and the occupational disease cases soared. It's seemingly by chance, but in fact inevitable. That the miner's right to life and right to health are infringed is the inevitable results of many factors stacking in a long-term. The government does not assume the due responsibilities, the employer escapes the liability, the miner's quality is to be improved and the social insurance system is not complete are the 
important reasons that caused the frequent infringement of the miner's right to life and right to health.

\subsection{The Government Does Not Take the Adequate Responsibility}

Ensuring the production safety, promoting the economic development and safeguarding the people's right to life, right to health and the property right are the basic responsibilities of the government. However, some law enforcement agencies not only do not do their due duty, but even are in cahoots with the coal mine owners ugly.

\subsubsection{The Government Officials Are in Cahoots with the Mine Owners}

There is great danger of the cahoots between the government officials and the mine owners. It not only corrupts the social values, but also affects the development of economic and social health. It is also an important reason for the frequent coal mine accidents. Some of the "degenerated" government officials forget their original responsibilities in the face of huge economic benefits. They cannot play the proper role, but even become a direct infringer against the miner's rights.

\subsubsection{The Market Access System Is Imperfect}

The market access standard is too low, which results in the small-sized mines with relatively worse basis for the production safety flooded. When an industry or market access standard is too low, there might be excessive or vicious inter-firm competition, and the result is bound to reduce the industry's average profit. (Sun, 2004) There's a huge safety risk with the small mines without the safe production license or those with a relatively weak basis for the production safety. Today in the United States, the coal mine industry has become a safe industry. However, in the 1930s, the U.S. coal mine deaths were more than 1,500 people every year. In the early 1970s, the United States began implementing the "Federal Coal Mine Safety Act", which has closed more than 2,000 small coal mines that cannot reach the required standards of small coal mines. (Wang, 2010) To protect the miner's right to life and right to health from the source, it's bound to enhance the market access standard, and to close the small coal mines that cannot meet the required standard. The labor, health, safety, industrial \& commercial, and judicial departments should assume their responsibilities and enforce the law strictly.

\subsubsection{The Management Has the Wrong Perception}

There is one kind of puzzling remarks saying that the mine accident is a normal phenomenon, as made by some people. Their reasons are: the mining industry itself is a high-risk industry, and it's more likely to cause injury than any other industries. Other countries are also facing the same problem. It is true that the mining industry itself is a high-risk industry, but not all countries will occur such amazing number of major accidents and extra serious accidents. Statistics showed that in 2003 , the nation's coal mine mortality rate per one million tons was 4.17 (per 1 million tons of coal mined, with 4.17 deaths of miners), which is 100 times of the United States, 30 times of South Africa, and 10 times of India. (Ma, 2006) As a result, although the mining industry is a high-risk industry, to some extent, it is feasible and necessary to prevent the accidents from happening.

\subsection{The Employers Escape the Responsibilities}

Employers should be the important responsible body to protect the miner's right to life and right to health. While they gain the huge profits at the expense of miner's right to life and right to health, they don't take the due responsibilities.

\subsubsection{Ignoring the Investment in Production Safety}

In China, a large number of coal companies ignore the investment in production safety, which results in a large number of coal mines do not have security. According to the preliminary statistics, just the arrear of "One Pass and Three Prevent" of the key state-owned coal mines are up to 4 billion. (Sun, 2004) I believe that the government should still increase the investment if we want to reverse the situation of the poor production safety basis of the coal mine companies in the near future. But we cannot simply rely on the government investment. The coal companies should be urged to spend more money into the production safety. For those who refuse to follow, they should be set a deadline for correction. For cases of gross violation, the mines should be closed. Meanwhile, the appropriate incentive mechanism should be established to reward the companies who have achieved the outstanding results in production safety.

\subsubsection{Failure to Abide by the Law}

That the employer does not strictly abide by the law is the most direct cause to the infringement of the miner's right to life and right to health. (Lin, 2006) In fact, the laws and regulations like "The Occupational Disease Prevention Law of PRC", "The Production Safety Law of PRC", "The Labor Law of PRC", "Employment Injury Insurance Regulations", "The Labor Union Law of PRC", "Coal Mine Safety Supervision Regulations", etc. have provided a relatively sufficient basis for the protection of the miner's right to life and right to health. However, a 
considerable number of laws and regulations have not been implemented. To strengthen the law enforcement and to punish the employers who are not in compliance with the laws and regulations, will not only protect the miner' $\mathrm{s}$ right to life and right to health, but also help maintain the authority of the law.

\subsubsection{The Weak Safety Consciousness}

In order to avoid the legal liability, the coal mine owners often employ the migrant works and the temporary workers with a relatively weak legal consciousness. The coal mine owners make every effort to reduce the costs and ignore safety, which leads to a serious loss of talents. At present, the China miner's working environment is very poor. They are lack of the necessary labor protection and the overtime working fatigue is widespread. However, their wages are much lower than the miners in many other countries. In China, the average monthly wage of China's coal miners is less than 2,000 Yuan. (Yang \& $\mathrm{Li}, 2005$ ) There is a severe imbalance between the miner's giving and income. This situation has caused a huge loss of the professional and technical personnel, so that the pre-existing production safety crisis becomes more severe.

\subsection{The Miners' Quality Is to Be Improved}

China's miners are generally less educated. Needs-to-be-improved quality of the employees has become one of the important factors to the frequent occurrence of the mine accidents. Data shows that among China's large and medium-sized coal mines above $300 \mathrm{k}$ tons, miners with middle school education count for $62 \%$, and the advanced engineering and technical personnel only count for $3 \%$. Among the large and medium-sized coal mines below 300k tons, the workers with secondary or more education are less than 3 people per ore. (Wang, 2007) Clearly, the educational degree and the technical level of the practitioners will directly affect the safety of mining production. Due to low access standard of the miners and the poor working conditions, majority of the miners are migrant works with a lower education level.

China's miners are with weak safety consciousness. Many miners do not have the basic safety knowledge and the occupational disease prevention and control knowledge. They do not even know the basic common sense like not to smoke in the mine. Few miners urge the employer to improve their environmental and health conditions. And there are fewer miners who conduct the regular health checks. Of course, due to the current labor surplus, the labor unions have not been playing its due role. It also led the miners not to afford to "bargain" with the employer for improving their security environment.

\subsection{Miners Are Drifted Away from the "Safety Net" of Social Insurance}

The social security should first protect the vulnerable groups. For this reason, in the United States and the other developed countries, the social security protection is mainly for the poor and the elderly, while working people's social security is mainly covered by the commercial insurance. However, in China, there is a strange phenomenon. The country's social security is mainly for the urban workers, but the protection to the laid-off and the unemployed are worse, as to the miners, it's even worse. (Cai, 2006) In fact, the miners' needs for the social security (in particular, for the basic element of it - the social insurance) are far more urgent than the urban workers'. In social insurance, what the miners need most is employment injury insurance.

\section{Protection Measures of the Miner's Right to Life and Right to Health}

In China, the mining industry is classified as a high-risk industry, and it ranks top in the first 5 high-risk industries. While in the U.S., the mining industry has become a safe industry. The same industry is generating the different results in different countries. For the existing problems, to protect our miners' right to life and right to health, we should take the following protection measures.

\subsection{The Government Should Be Responsible for the Protection}

The right to life and right to health are the fundamental personal rights of citizens, the government should take the appropriate responsibilities to protect them, which is obligatory.

\subsubsection{The Government Should Take the Responsibilities Actively}

The government should not only function as the defending party to the miner's right to life and right to health, they should also assume a positive obligation to protect them. The jurisdiction of the government should be involved in the whole process including the mine production management, the safety management and the disaster management, but not just the "disaster rescue" and the "chasing punishment" after the accident. (Yang, 2004) Currently, the government often acts as a "fireman", but its role does not reflect the prevention function in the administrative law enforcement. By raising threshold of the market access system, the government can kill the small coal mines with safety risks in the cradle, and can prevent the risk of accidents from the root. 


\subsubsection{The Government Should Improve the Market Access System}

Many countries have recognized the need to improve the market access system, and are implementing it boldly, which is the good experience we can learn from. In the United States, to obtain the right to coal mining, the investors need to pay the resources dividends per competitive pricing in one go at first. (Wang, 2010) Such an approach, not only reflects the principles of fairness and justice of the market economy, but also ensures the coal mining investors who have obtained the access right to have the sufficient financial resources. It is worth our learning.

\subsubsection{To Eliminate the Wrong Perception of the Management}

The mine accidents are not the inevitable price of the economic development. "If the economic development at the expense of ecological environment deterioration is like draining the pond to get all the fish, then at the expense of human health and even life in exchange for economic development is nothing but killing the goose that lays the golden eggs." (Huang, 2007) The fundamental purpose of the economic development is to better protect the citizens' health and life. At the expense of human life in exchange for the economic development will create serious social problems, and ultimately lose directions. The economic development will be stalled.

\subsection{The Employer Should Bear the Due Responsibilities}

\subsubsection{To Increase Investment in the Production Safety}

Increasing investment in the production safety mainly relies on the enterprise self-financing. By increasing the market access standards, the government should ensure the mining companies that have obtained the access right set aside enough money into the production safety. The current status is that the key state-owned coal mines have up to 4 billion of debts in the area of production safety. Neither the government nor the enterprise can come up with the funds of this magnitude in a short-term. However, with the rapid development of China's economy, the energy consumption, especially consumption of coal has increased year by year, which cannot afford to close these key state-owned coal mines in a long run. In this case, the introduction of external capital into the coal market has become an inevitable choice. At present, almost all large and medium-sized coal mines are owned by the state. We may transfer part of the state-owned shares to get the money for filling the old debts of the safety. (Wang, 2010) In fact, by raising fund from many resources, efficiently using the funds raised, and making every effort to increase the investment in the production safety, the enterprise can not only protect the miners' rights to life and right to health, but also bring the enormous benefits.

\subsubsection{To Hold the Employer's Legal Responsibility}

The most direct cause to the miner's right to life and right to health missing is that the employer's not managing according to law strictly. For the misconduct or negligence of the employer and the person in charge, it must be severely punished. The good news is that the newly issued "Social Insurance Law" and the newly revised "Employment Injury Insurance Regulations" clearly regulate that the employer and the person in charge should bear the legal responsibilities for their illegal misconduct. But the specific procedure and the specific principle of attribution should be further defined. How to hold the legal responsibility of the employer should be tracked into the rule of law. Only through strengthening the law enforcement and punishing the employer and the person in charge for their not acting according to the law, employers can be encouraged to recognize the seriousness of the law, and to protect the miners' right to life and right to health according to the law.

\subsubsection{To Enhance the Safety Awareness}

Comparing to the vulnerable group of miners, the mine owners should enhance the safety awareness more. Because the mine owners get the great benefits, at the same time, they are more capable and should have more responsibilities to implement the safety awareness in the daily work. With the established safety awareness, the mine owners will no longer sacrifice the miner's right to life and right to health in exchange for the economic profit. The mine owners will increase the investment in mine safety, cherish talents and take active measures to retain talents. They will strengthen the technical training and conduct self-examination on the coal mine safety. The mining accidents and the occupational diseases will be eliminated from the source.

\subsection{The Miner's Quality Should Be Improved}

The coal mining enterprises belong to the high-risk industry. Their technical management personnel who carry out the coal mining must not only understand the engineering, but also have the ability to control a variety of risks, which is different from other industries. As a result, a large number of professionals are required. At present, a serious talent crunch is being faced. The talent crunch has increased the probability of occurrence of the coal mine accidents. In order to resolve the talent crunch, we should vigorously develop the professional and 
technical personnel and effectively increase their income, improve the benefits and the living environment of the employees. (Wang, 2007) 23 A considerable number of technical personnel will provide protection to the miner's right to life and right to health from the technical perspective.

Miners themselves should sign the labor contracts with the mine owners when they are onboard. They should also consciously learn the basic safety and occupational disease prevention and control knowledge, and avoid illegal operations. Miners should urge the employer to improve their environmental and health conditions, and conduct regular health check. Although the power of the miners is extremely weak, if each miner is established with the safety awareness, it can create synergy to avoid the mine accidents to some extent.

\subsection{The Establishment of the Social Insurance System for the Miners}

The establishment of the social insurance system for the miners is the inevitable method to improve China's social insurance system and to effectively protect the miner's right to life and right to health.

To expand the insurance coverage rate for the miners in China is both necessary and feasible. Many western countries with a more perfect social insurance system are very focused on broadening the coverage of the social insurance. Such an approach is not only consistent with the basic values of social insurance, but also follows the rule and principle of the social insurance. (Huang, 2004) China's "Social Insurance Law" also states that the country's social insurance system should adhere to the principle of wide coverage. By expanding the insurance coverage rate of the miners and diversifying the risks, the government can provide more comprehensive protection to the miners.

At present, subjectively, we are more willing to provide miners with the comprehensive and high standard social insurance. However, due to various constraints, we can only establish a low standard and a basic type of social insurance. The priority is to establish the employment injury insurance and the medical insurance, especially the comprehensive arrangement for the serious disease insurance. This is the most urgent need of the miners, but also the basic insurance to protect the miners' right to life and right to health and the bottom line. The old-age insurance follows as the next. Since majority of the miners are young people, they have no proximate needs to this insurance temporarily. (Hao, 2007) The unemployment insurance and the maternity insurance are the last. The level of social insurance will go through a process from low to high.

\section{Conclusion}

Mining in China is a high-risk industry, but in some developed countries, it has become a safe industry. In other words, in many cases, the phenomenon of the infringement of the miner's right to life and right to health should be avoided, and it's completely avoidable. By implementing the following specific measures, i.e. the government, the employers and the miners doing their own duty, and the establishment of special social insurance system for the miners, the unnecessary damage to the miners in China will be avoided. It is also conducive to providing the protection to the miners' right to life and right health in China.

\section{References}

Cai, J. W. (2006). Survival of Chinese migrant workers. Bei Jing: Contemporary China Publishing House.

Hao, G. Y. (2007). The migrant workers in urbanization. Bei Jing: China social science press.

Huang, L. P. (2007). Difficulties and their solution of safeguard rights in industrial accident. Fellow Workers, 1, 41-43.

Huang, X. X. (2004). Research on the injury insurance legal system of China. Southwest University of Political Science \& Law, 23-24.

Lan, F., \& He, X. (2010). Pneumoconiosis: it is endless to protect rights. New Century Weekly, 2, 72-74.

Lin, Z. (2006). A study of the legal institutions of citizens' fundamental human rights. Bei Jing: Bei Jing University Press.

Ma, S. Z. (2006). Reasons of the frequent occurrence of mine accidents. Mining \& Processing Equipment, 5, $13-15$.

State Administration of Work safety. (2011). Analysis of non-coal mine accidents in 2010. Retrieved from http://www.chinasafety.gov.cn/newpage/Contents/Channel_4181/2011/0309/125710/content_125710.htm

Sun, S. H. (2004). Strengthen the construction of the miners safety system. Research on Economics and Management, 1, 22-27.

Wang, D. T. (2007). The talents crisis of the frequent occurrence of mine accidents. Chinese Talents, 1, 22-23. 
Wang, R. (2010). Explore the root of coal mine accidents. Retrieved from http://www.anquan.com.cn/Wencui/ guanli/meikuanglw/200609/44859.html

Yang, F. C. (2004). Governmental duty for mine accidents. Decision-making and consultation, 12, 28-29.

Yang, Y. Y., \& Li, H. M. (2005). Mine accidents torture institutional arrangements. Labor and Social Security in China, 4, 10-12.

\section{Copyrights}

Copyright for this article is retained by the author(s), with first publication rights granted to the journal.

This is an open-access article distributed under the terms and conditions of the Creative Commons Attribution license (http://creativecommons.org/licenses/by/3.0/). 